\title{
CAMA
}

Centre for Applied Macroeconomic Analysis

\section{Government bond yields at the effective lower bound: International evidence}

\section{CAMA Working Paper 32/2017 April 2017}

\section{Domenico Lombardi}

Centre for International Governance Innovation, Canada

\section{Pierre L. Siklos}

Wilfrid Laurier University, Balsillie School of International Affairs, Centre for International Governance Innovation, Canada and

Centre for Applied Macroeconomic Analysis, ANU

\section{Samantha St. Amand}

Centre for International Governance Innovation, Canada

\section{Abstract}

Empirical evidence on the potential impact of central bank policies on government bond yields at the effective lower bound (ELB) is presented for nine economies. We quantify the content of central bank communications and consider international policy spillovers. At the ELB, yields at the medium-to-longer end of the yield curve remain responsive to news for a few years after the ELB is reached. Yields become more sensitive to the content central bank communication at the ELB. Our results provides further evidence that central bank communication is an important element of monetary policy making when the interest rate tool loses efficacy. 


\section{Keywords}

\section{JEL Classification}

E52, E58, G12, F42

Address for correspondence:

(E) cama.admin@anu.edu.au

\section{ISSN 2206-0332}

The Centre for Applied Macroeconomic Analysis in the Crawford School of Public Policy has been established to build strong links between professional macroeconomists. It provides a forum for quality macroeconomic research and discussion of policy issues between academia, government and the private sector.

The Crawford School of Public Policy is the Australian National University's public policy school, serving and influencing Australia, Asia and the Pacific through advanced policy research, graduate and executive education, and policy impact. 


\title{
GOVERNMENT BOND YIELDS AT THE EFFECTIVE LOWER BOUND: INTERNATIONAL EVIDENCE*
}

\author{
Domenico Lombardi, Pierre L. Siklos and Samantha St. Amand \\ [MARCH 2017]
}

* This is a CIGI-sponsored research project. The opinions in the paper are those of the authors and not the institutions that supported this research. Domenico Lombardi is Director of the Global Economy program at CIGI, Samantha St. Amand is a Senior Research Associate at CIGI, and Pierre Siklos is a CIGI Senior Fellow, and Professor of Economics at Wilfrid Laurier University and the Balsillie School of International Affairs. Previous versions of this paper were presented at meetings of the Canadian Economics Association, the Asian Finance Association, the World Finance Conference, the Southern Finance Association, and the Society for Nonlinear Dynamics and Econometrics. Comments by the Editor and an anonymous referee are gratefully acknowledged. 


\begin{abstract}
Empirical evidence on the potential impact of central bank policies on government bond yields at the effective lower bound (ELB) is presented for nine economies. We quantify the content of central bank communications and consider international policy spillovers. At the ELB, yields at the medium-to-longer end of the yield curve remain responsive to news for a few years after the ELB is reached. Yields become more sensitive to the content central bank communication at the ELB. Our results provides further evidence that central bank communication is an important element of monetary policy making when the interest rate tool loses efficacy (JEL: E52, E58, G12, F42).
\end{abstract}

\title{
Domenico Lombardi
}

Centre for International Governance Innovation

67 Erb Street West, Waterloo, ON, Canada N2L 6C2

dlombardi@cigionline.org

+15198852444 ext. 7227

Pierre L. Siklos (corresponding author)

Wilfrid Laurier University, Balsillie School of International Affairs, Centre for International

Governance Innovation, and Centre for Macroeconomics Analysis (CAMA)

75 University Avenue West, Waterloo, ON, Canada N2L 3C5

psiklos@wlu.ca

+1 5198840710 ext. 2559

\section{Samantha St. Amand}

Centre for International Governance Innovation

67 Erb Street West, Waterloo, ON, Canada N2L 6C2

sstamand@cigionline.org

+1 5198852444 ext. 7232 


\section{INTRODUCTION}

Following the international financial crisis of 2007-9, a small, but systemically important, group of central banks in advanced economies reduced their policy rates to the zero lower bound (ZLB). As bank lending and economic activity remaining weak in many countries, some central banks even introduced negative policy interest rates. As a result, the literature has begun to refer to the effective lower bound (ELB) for policy rates. While prior to the crisis, only the Bank of Japan kept the interest rate indicative of its policy stance at the ZLB; since 2008, several other central banks have followed suit, including the Bank of Canada (BoC), the Bank of England (BoE), the European Central Bank (ECB), the Swedish Riksbank, the Swiss National Bank (SNB), and the US Federal Reserve. Central bankers in these economies have at the same time become increasingly vocal about the ability of monetary policy to remain effective after the ELB is reached (e.g., Bernanke 2012; Carney 2013; Svensson 2010; Yellen 2014). Of course, many of these same central banks have also turned to unconventional monetary policies (UMPs), partly to counteract this impression that monetary policy is ineffective when rates have reached the ELB.

Indeed, UMPs have helped dispel the impression that monetary policy could not be effective after reaching the ELB. The works of Christensen and Rudebusch (2012), Gagnon et al. (2011), Krishnamurthy and Vissing-Jorgenson (2011), Joyce et al. (2011), and De Rezende et al. (2015) represent only a small sample of the significant literature that investigates the impact of UMPs on sovereign bond yields and other assets involved in various asset purchase programs.

Alongside the implementation of UMPs, central banks have increasingly utilized the timing and content of announcements as an additional element of their monetary policies. The increased reliance on such announcements has also contributed to changing attitudes about the ability to influence the stance of monetary policy when the ELB on nominal policy rates is reached. 
Indeed, a small number of central banks began to resort to forward guidance-communicating conditional commitments to future policy paths - to further influence expectations and the effectiveness of monetary policy. Nevertheless, due to the continuous doubts regarding their effectiveness, these strategies remain controversial (e.g., Ball et al. 2016; Filardo and Hofmann 2014). However, while many recognize the importance of verbal interventions of this nature, few have actually conditioned their findings on the impact of central bank communication on sovereign bond yields, as is done in the present study.

UMPs are aimed at influencing yields across the term structure through direct and indirect channels. Of course, it has long been known that news, in the form of macroeconomic announcements reflecting underlying economic conditions, influence yields on financial instruments with different maturity structures. This was true even before UMPs were implemented. However, if we are to evaluate the effectiveness of monetary policy at the ELB, the challenge is to properly identify whether market participants are less responsive to news because central banks are at, or near, the ELB. In this connection, it then becomes policy relevant to estimate whether and how responsive yields of varying term structures are to such news and announcements. This paper provides international evidence of the data dependence of yields for select short- and long-term government bonds. We address this issue by looking at the reactions of sovereign bond yields to news events and central bank communications for samples that precede and follow the twin financial crises of 2007-9 and the 2010-12 euro area sovereign debt crisis.

In our methodology, the responsiveness of yields to central bank announcements at the ELB depends on the selection of a benchmark period when market participants' responses to such news was considered 'normal'. In other words, the extent to which monetary policy is 
constrained is quantified in relation to a period when policy rates were sufficiently far away from the ELB that it would not affect markets’ reactions to news. Swanson and Williams (SW; 2014a, 2014b) propose such a methodology to empirically assess the constraint posed by the ZLB for the US, the UK and Germany. This paper relies on a modified version of their approach.

Our study departs from SW (2014a, 2014b) in three important respects. First, our metric for news effects is significantly broadened to include variables that quantify the content of press releases and meeting minutes published by central banks. In so doing we rely on an algorithm that converts vectors of words into a numerical indicator that can be used in econometric estimation. Second, we extend their earlier analyses by adding data for Canada, Sweden, Switzerland, and the euro area. This allows for international evidence about the impact of the ELB across a wider spectrum of monetary policy strategies. Third, unlike SW (2014a, 2014b), our estimates are also conditioned on international spillover effects. Though we focus on the content of central bank communication on domestic yields, spillover effects should not be ignored (also see the on-line annex).

To preview our results, we find that the sensitivity of yields to news falls at the ELB. Most medium- to longer-term yields become constrained around 2012, that is, three years after most central banks in our study reached the ELB, but there are some exceptions. For example, 10-year government bond yields in Sweden and the UK retain 'normal' responsiveness to news-relative to a benchmark period where 'news response' is deemed normal (i.e., consistent with pre-crisis types of responses) — while yields in the US and Canada retain some responsiveness to news relative to their benchmark periods. There is also evidence that Swedish and Swiss yields became more responsive to news after their respective central banks introduced negative policy rates. 
While sensitivity of yields to news generally decreased at the ELB, yields need not be less responsive to all forms of news. Indeed, we find that government bond yields became more responsive to shocks in the content of central bank communication at the ELB, especially at the longer-end of the yield curve. Therefore, our results provide further evidence that central bank communication is an important element of monetary policy making when the interest rate tool loses efficacy.

The rest of the paper is organized as follows. The next section provides an overview of the relevant literature on the ELB and the associated monetary policy challenges. Section 3 is devoted to the methodology and data. Section 4 covers a few stylized facts and describes our main findings. The paper concludes with a brief summary of the results and the implications for the effectiveness of monetary policy at the ELB.

\section{LITERATURE REVIEW}

Under 'normal' circumstances, news moves markets. ${ }^{1}$ Further, while news does arrive in several forms, the extant literature relies exclusively on macroeconomic and financial announcements (e.g., employment reports, CPI inflation releases, and so on). Gürkaynak, Sack and Swanson (2005a, 2005b), for instance, have made the case that such announcements represent an incomplete representation of the sources of surprises in monetary policy. This idea is especially evident as central banks increasingly rely on verbal announcements or the eventually publicised minutes of the policy committee meetings that accompany policy rate decisions to steer monetary policy. These channels provide additional, potentially relevant sources of news.

\footnotetext{
${ }^{1} \mathrm{By}$ 'normal' we are referring to interest rate levels that are sufficiently above the ELB so that the concerns that are the subject of this study are no longer relevant. Of course, what is considered normal can well be period-specific. As we shall see, however, our results are robust to the selection of reasonable thresholds above which yields are deemed to be 'normal'.
} 
Moreover, there is a large literature that explores the impact of monetary policy decisions and news events on yields along the term structure. But other than for Japan, where the Bank of Japan has kept its policy rate near zero for well over a decade, or Switzerland, which has also experienced bouts of low inflation and interest rates over the past several years, there are relatively few studies that ask whether monetary policy can retain its influence when policy rates effectively fall to zero or below. ${ }^{2}$ As recent as a decade ago, only small samples were available to assess financial market reactions at the ELB, which brought Bernanke, Reinhart and Sack $(2004,2)$ to comment that "systematic empirical evidence on the potential efficacy of alternative policies is scant."3

Surveying the empirical research on the financial market effects of quantitative easing (QE), Gagnon (2016, Table 1) identifies that 18 of 24 are event studies, while only a small handful (three to six) perform time series analysis. But, now that several more central banks have driven policy rates near the ELB and over a longer period, there is much greater scope for a time series exploration of the impact of news at very low interest rates.

Event studies have their challenges (e.g., MacKinlay 1997), but time series analyses are not without problems of their own. Perhaps the greatest advantage of the time series approach is that it does not require the investigator to take a stand on the window of time over which a news event or policy announcement is thought to influence yields. Indeed, the selection of the window

\footnotetext{
${ }^{2}$ There is an implicit assumption, informed by the well-known Fisher equation, that nominal interest rates and (expected) inflation move in the same direction. Indeed, one worry that emerged during the 1990s concerning the prospect of low inflation is that it might increase the chances of hitting the ZLB (see, for example, Summers 1991). However, the two need not go hand in hand. For example, the 1950s and early 1960s were a period of relatively low inflation but the risks of the ZLB were low. However, recent evidence suggests that previous research understated the threat of reaching the ZLB (Chung et al. 2012).

${ }^{3}$ Given the small number of observations and historical examples that combine low inflation with low interest rates, many of the pre-2007 studies rely on model simulation results. For a comprehensive early review of the literature for the US, Canada and Japan, see Amirault and O’Reilly (2001).
} 
limits the possibility of a delayed market reaction either because investors have yet to digest existing information or because they revisit and revise previously held beliefs. ${ }^{4}$ On the other hand, the time series approach is complicated by the possibility that estimates might be contaminated by the omission of certain factors or events that influence yields. The methodology adopted in this study is suitable under the circumstances as it allows for an examination of a wider array of determinants of policy decisions over time as opposed to judiciously chosen events. It also allows for a quantitative measurement of the time-varying sensitivity of yields at the ELB. In any event, we do take steps to limit the risks that arise from a time series approach as they relate to the issues investigated. Moreover, our methodology permits a more direct comparison with the recent evidence (e.g., SW 2014a, 2014b).

Also related to these issues is the choice of the sampling frequency. Some research considers the financial market impact of UMPs at the intra-daily sampling frequency (e.g., Gilchrist et al. 2014; Rogers, Scotti and Wright 2014). ${ }^{5}$ One important reason for observing daily effects is that monetary policy announcements and reactions potentially cover several time zones. Indeed, there are reasons to expect these effects to linger for longer because of the phenomenon of rational inattention (e.g., Sims 2003; Wiederholt 2012). Accordingly, daily data are capable of adequately capturing the impact of new information on financial markets, including cross-border effects of news announcements that originate in a different part of the world.

\footnotetext{
${ }^{4}$ Whether this is the result of a form of rational inattention is unclear. Nevertheless, the notion that not all agents react to news at the same time is a possibility that is now routinely admitted. We do not, however, pursue this line of investigation any further.

${ }^{5}$ The use of intra-daily data raises some technical challenges. For example, daily data are often non-stationary in levels but stationary in first differences; the time series properties of intra-daily data can be rather different (Tsay 2010).
} 
If the ELB is problematic for the effectiveness of monetary policy, then how can the constraint be overcome? Suggestions were already being made several years ago (e.g., Blinder 2000; Buiter 2009; Goodfriend 2000; McCallum 2000). Some central banks attempted to influence mediumto long-term yields; however, several observers were skeptical that this would be an effective strategy (e.g., Blinder 2000; Ueda 2005). The experience at the Bank of Japan also casts a shadow on the power of these kinds of policies (e.g., Kuttner and Posen 2004; Bernanke, Reinhart and Sack 2004).

Forward guidance is another policy tool used to prevent monetary policy from being constrained at the ELB. These verbal tools work by communicating when the policy stance could be changed or reversed. But, as there is a critical element of conditionality about these promises, the effectiveness of such policies may diminish, especially if the commitment is not viewed as being credible (Woodford 2012). ${ }^{6}$

Despite extensive research on UMPs, few studies have specifically examined the extent to which yields were constrained during the ELB period. SW (2014a, 2014b) offer an empirical methodology that identifies whether or not yields are constrained. On the experience in the US, they report that yields on Treasuries were "surprisingly" responsive to news until 2011 when the Fed began issuing various forms of forward guidance. Therefore, while the federal funds rate reached the ELB in late 2008, monetary policy continued to be effective. They also reach a similar conclusion using data on the UK and Germany; just as Winkelmann, Bibinger and Linzert (2016) do in their study of the euro area.

\footnotetext{
${ }^{6}$ Filardo and Hofmann (2014) is a recent survey of the experience with forward guidance in the US, Japan, the UK, and the ECB. For the Canadian case, see Siklos and Spence (2010) and He (2010). For a more critical view of the earlier US experience, see Levin et al. (2010).
} 
But this literature omits an important source of news: new information in central bank communications. ${ }^{7}$ This type of news is important because, although monetary policy interest rates may be constrained, monetary conditions continue to change over time. Several approaches have been applied to measure the content of central bank announcements. One frequently used method is to manually construct variables aimed at capturing the intentions of policy communications. An early application of this approach was performed by Romer and Romer (1989, 2004) who used a 'narrative approach' to complement quantitative data to extract US Federal Open Market Committee (FOMC) intentions for the federal funds rate. Typically, these studies assign a negative (positive) value to statements that are perceived to be dovish (hawkish) based on their own interpretation of the central bank’s communication (e.g., Gerlach 2007) or the interpretation of the communication by news reports (e.g., Ehrmann and Fratzscher 2007; Jansen and De Haan 2010). This approach to coding policy intentions captures asymmetry in monetary policy communications, however, it is a subjective measurement that is bounded by a predetermined, ordinal scale. Another approach frequently used in the literature is to derive the interpretation of monetary policymakers' intentions from financial market reactions using principal component analysis (e.g., Gürkaynak, Sack and Swanson 2005a, 2005b). While this approach generates a continuous variable that is not clouded by hindsight, similar to event study methodologies, it requires defining a time period within which financial market volatility is considered relevant to the announcement.

More recent research applies text analysis methods to quantify the content of central bank communications. De Carvalho et al. (2016), for example, quantify the content of US FOMC

\footnotetext{
${ }^{7}$ Two recent studies have analyzed the impact of US FOMC communications at the ELB (Davis and Wynne 2016; De Carvalho et al. 2016). These studies use a different approach to measuring communication than the present study. They find that US FOMC communications continued to impact longer-term yields during the period where the federal funds rate was at the ELB.
} 
statements by calculating a ratio of the number of times 'hawkish' and 'dovish' appear in news articles surrounding an announcement. We also rely on semantic-based measurements, and use a 'dictionary' technique to quantify the content of central bank communications (see Hart, Childers and Lind 2013; Loughran and McDonald 2011). Instead of coding central bank statements based on a narrow list of words (i.e., hawkish/dovish), the dictionaries define a collection of words that aim to convey meaning along specific dimensions of central bank statements. As Meade, Burk and Joesselyn (2015) argue, US policy makers view the minutes “...as providing insight about the breadth of views.” Furthermore, since meeting participants provide input before the final draft is published (Danker and Luecke 2005), the intention and, therefore, the content of the document ought to reflect the views of FOMC members.

\section{DATA AND ECONOMETRIC SPECIFICATIONS}

\section{$\underline{\text { News }}$}

Our sample includes countries that have reached the ELB in policy rates. The economies that have, in recent years, come closest to the ELB at one time or another include Canada, the euro area (our sample includes euro area yields, ${ }^{8}$ Germany and France), Sweden, Switzerland, the United States and the United Kingdom. All the economies in the sample have, at least in de jure terms, flexible exchange rates and open capital markets. ${ }^{9}$ Our sample period begins in January 2001, ends in March 2015, and consists of daily data. Since the financial crisis in the US began some time in 2007, while the sovereign debt crisis in Europe begins in 2010, our sample also

\footnotetext{
${ }^{8}$ The data for the euro area yield curve is retrieved from the ECB. The term structure is estimated by imposing a functional form between interest rates and time to maturity, using an approach proposed by Svensson (1994). Refer to ECB (2008) for more information.

${ }^{9}$ Switzerland typically operates with a flexible exchange rate, however, from 6 September 2011 to 15 January 2015, the Swiss National Bank imposed a minimum exchange rate with the euro of 1.20 Swiss Francs. Denmark also lowered its policy rate to the ELB; but it is not part of this study because it maintains a fixed exchange rate with the euro.
} 
covers a significant span of time when financial markets operated more or less normally. ${ }^{10}$ Table 1 provides details about the time span where the ELB was in operation in the economies considered in this study. ${ }^{11}$

[insert Table 1 around here]

Financial markets are forward looking; therefore, anticipated economic activity should be priced into assets (Kuttner 2001). Our methodology hypothesizes that markets should only react to the unexpected or 'surprise' components of each data release. As such, our study is concerned with the sensitivity of yields to two sets of surprise news variables, conditional on other control variables (see below). The first set is a vector of the surprise component of macroeconomic news announcements. Using a methodology similar to that adopted by SW (2014a; 2014b), and several others, surprise macroeconomic announcements are constructed by subtracting a consensus forecast from the actual data release and normalizing the data by the full sample standard deviation. ${ }^{12}$ Estimation of news effects relies on taking a stand on expectations. Of course, expectations are not unique. Forecasters can disagree (e.g., Siklos 2013, and references therein) and this can have implications for studies such as ours. Therefore, there is the potential for mismeasurement. Indeed, there does exist a large literature supporting the notion that combining forecasts yields superior forecasts (e.g., Armstrong 2001), though the reason remains unclear. Nevertheless, as long as the forecasts used are generally unbiased, any mis-measurement is likely

\footnotetext{
${ }^{10}$ See one of several crisis timelines. For example, https://www.stlouisfed.org/Financial-Crisis (Federal Reserve Bank of St. Louis).

${ }^{11}$ Japan is excluded because the sample period does not extend far enough to create a significant benchmark where yields were not constrained by the ELB.

${ }^{12}$ It is conceivable that the magnitude of surprise macroeconomic announcements experienced significant changes throughout the period owing to the 2007-9 international financial crisis. However, there were few statistically significant differences in macroeconomic surprises between periods (see on-line annex). We performed sensitivity analyses to verify whether normalizing the variable using different sample periods, versus normalizing using the full sample, influenced the regression results, and found no statistically significant differences.
} 
to be noise and would not materially impact the conclusions. We believe this assumption is valid for the data set employed in the present study. ${ }^{13}$ The indicators selected for the analysis are typically considered to be 'market-moving,' that is, they are believed to have a same day impact on domestic and global yields; they are also similar to those employed by SW (2014a; 2014b).

The second set of variables is more novel under the circumstances. We evaluate the changing content of monetary policy communications as an additional source of news. To quantify central bank communication, we rely on an algorithm that measures the content of central bank press releases and meeting minutes based on a large dictionary of terms. The dictionaries we use include a combination of those constructed by Loughran and McDonald (2011) based on financial texts, and DICTION (see Hart, Childers and Lind 2013), originally created using political texts. Specifically, three dictionaries are defined, grouping words in categories that aim to capture meaningful aspects of central bank communication: optimism, pessimism and certainty. These dictionaries were augmented with language commonly used in central bank communication. In addition, words that are more ambiguous in the context of central banking, such as 'risk', 'unemployment', 'surprise', and so on, were removed from the dictionaries. In general, the optimism dictionary aims to capture language that signals improved economic conditions or outlook, while the pessimism dictionary includes language that may indicate that economic conditions have deteriorated or that the outlook has worsened or even turned negative. Importantly, we argue that the content variables are crucial for capturing the monetary policy committee's interpretation of economic conditions and their potential impact on future monetary policy decisions. For this reason, the content variables offer additional information beyond numerical economic forecasts or macroeconomic data releases.

\footnotetext{
${ }^{13}$ We are grateful to the referee for pointing out the issue.
} 
The third content variable is labelled ‘certainty'. This variable brings together two meaningful dimensions of central bank communication: it subtracts language that conveys uncertainty and/or disagreement from language that conveys agreement and/or certainty. Central bank communication primarily aims to achieve two goals: to improve the effectiveness of monetary policy by delivering clear information about current policy decisions and the potential future policy path, and to reduce uncertainty in financial markets (e.g., Blinder 2008). The uncertainty variable aims to capture the latter; this dictionary includes words that are used to express doubt or a lack of confidence in statements. Dissent (or agreement) improves information on the former, and has proved to be useful for forecasting future monetary policy decisions (Riboni and Ruge-Marcia 2014). Analyzing the content of the texts may indeed be preferable to simply tallying the vote count for monetary policy decision, as voting patterns have been found to be a poor measure of actual level of disagreement for the US FOMC (Meade 2005); in addition, several central banks do not reveal voting information (e.g., ECB) or do not take a formal vote (e.g., BoC). We use the DICTION 6.0 software to calculate the percentage of words that convey optimism, pessimism and certainty as a percentage of the total words of the text; the 'content' variables are therefore continuous, and are equal to zero on days where the central bank does not release a communication. The on-line annex elaborates on the content and construction of the dictionaries.

\section{Econometric Estimates of News Effects}

The standard model to evaluate the sensitivity of yields to surprise news events (e.g., Gürkaynak et al. 2005a, 2005b) posits that the unanticipated component of macroeconomic data releases is the principal determinant of changes in yields. An extended version of their model can be written as follows: 


$$
\Delta y_{t}=\alpha+\gamma Z_{t}+\beta X_{t}+\delta C_{t}+\varepsilon_{t}
$$

where $\Delta y_{t}$ is the daily change in a government bond yield, $z_{t}$ is a vector of dummy variables capturing monetary policy news events and $X_{t}$ is a vector of surprise components of macroeconomic data releases. Some news events, such as days when a monetary policy committee meets, are not surprises. However, even if the timing of these events is known in advance there can be a surprising outcome to the meeting, either because of changes in the verbal content of the announcements or because a policy change is decided. This is why it is important to extend the standard specification by adding a vector capturing the verbal content of central bank announcements via a proxy for the content of policy committee press releases and meeting minutes $\left(C_{t}\right){ }^{14}$

The sample period starts in January 2001 for most events in the US and March 2003 for the UK and the euro area economies. For the US, $X_{t}$ includes only domestic surprises in economic data releases. For the UK and the euro area, both domestic and US surprises are used; and for France and Germany, domestic, euro area, and US data release surprises are included. For Canada, only US surprises are used; and for Switzerland and Sweden, both US and euro area surprise data are used. ${ }^{15}$ The fact that domestic data for macroeconomic releases are unavailable for the smaller economies in our sample is not as great a disadvantage as one might think, since news releases often overlap with releases for major economies. Moreover, announcements from the major economies potentially have an outsized influence on the sovereign yields of small-open economies. Indeed, global capital markets are responsive to US economic conditions and yields

\footnotetext{
${ }^{14}$ To reduce noise, we drop observations on dates where a news event does not occur; that is, when $Z_{t}, X_{t}$ and $T_{t}$ are all equal to zero. However, we also ran the regression on the full dataset and the results were unchanged.

${ }^{15}$ Some news is released after financial markets in other time zones have closed; for example, FOMC press releases and meeting minutes are released at 2pm EST when markets in Europe are closed (8pm CET). These events were appropriately adjusted to represent a shock on the following trading day.
} 
respond to US news events (e.g., Lombardi, Siklos, and St. Amand 2016). Lack of sensitivity to US news events would therefore suggest domestic yields are constrained when policy rates are at the ZLB.

The content variables are also standardized to capture the impact of a 'surprise' in the language of a release. It is for this reason that press releases and meeting minutes are included in the analysis, but not central bankers' speeches. Press releases and meeting minutes offer a consistent means of communication, that varies due to deliberate changes in communication (i.e., press releases) or changes in the conversation (i.e., minutes); a 'surprise' element can therefore be extracted based on changes in the language used in the communication. The surprise element is measured by the standardized variable — mean of zero and standard deviation equal to one. ${ }^{16}$

To isolate the impact of the content of central bank press releases, $Z_{t}$ is a set of dummy variables for the dates of key monetary policy communications and important UMP announcements. One variable captures the dating of monetary policy committee meeting press releases, another captures the release date of monetary policy committee meeting minutes (where available), and a final dummy is used to account for announcements of UMPs for the US, the UK and the euro area. For the US, there is an additional dummy variable to capture the winding down of the US Fed’s QE policy, or 'tapering' announcements, since it is plausible that the QE and tapering announcements may have asymmetric effects on domestic as well as on foreign yields. These

\footnotetext{
${ }^{16}$ Two other measures of surprise were used to test the sensitivity of the results. One alternative measurement is the change in the content variable from one communication to the next. The second subtracts the pre-crisis median; the content of communication before the crisis could be taken as a sort of benchmark, where a deviation from this level could be interpreted as a shock. The results remain unchanged.
} 
dummy variables are equal to one the day of and day after an event. ${ }^{17}$ Further information on specific variables, sources of data, and summary statistics is relegated to an on-line annex.

SW (2014a, 2014b) generalize equation (1), which serves as a benchmark of sorts, and consider non-linear extensions. In most cases, however, they conclude that $\beta$ is constant. Yet, the prior is that the impact of news (and additionally here, the content of central bank announcements) on asset prices can be time-varying. Moreover, at the ELB, there is a strong possibility that the response is non-linear. ${ }^{18}$

We chose a specification that permits non-linearity to enter via a behavioral expression that captures a common determinant of the sensitivity of yields to news. Accordingly, we report results based on regressions of the form:

$$
\Delta y_{t}=\alpha+f\left(\Theta_{\mathrm{t}}\right)\left[\gamma Z_{t}+\beta X_{t}+\delta C_{t}\right]+\varepsilon_{t}
$$

where $f\left(\Theta_{\mathrm{t}}\right)$ denotes a function that relates variables believed to capture yield sensitivity. More precisely:

$$
f\left(\Theta_{\mathrm{t}}\right)=\theta+\phi \Theta_{\mathrm{t}}
$$

Equations (2) and (3) are jointly estimated. We assume that $\Theta_{t}$ is a vector consisting of the first principal component of the available domestic yields at various terms to maturity, the (10-day) rolling standard deviation of the first principal component, and a measure of global uncertainty, captured by the (10-day) rolling standard deviation of the first principal component of US treasury yields at various terms to maturity. As identified by SW (2014b), the sensitivity of yields may depend on the actual level of yields. News can impact yields across the term

\footnotetext{
${ }^{17}$ Other variants were considered with no impact on the conclusions. This coding is consistent with the literature (Fratzscher, Lo Duca and Straub forthcoming), and is preferable for a sample that spans several time zones.

${ }^{18}$ As explained in SW (2014a) there are relatively few macroeconomic announcements per year. In addition, there are typically only 4 to 12 central bank announcements or press releases per year. Hence, rolling or recursive estimates would not be terribly informative.
} 
structure; it is therefore appropriate to use the first principal component, which extracts common movements in yields, as a representative of the level of yield. The volatility of the first principal component is meant to capture the effects of uncertainty on yield movements. ${ }^{19}$ We do not impose sign restrictions on $\phi$ in equation (3) because it is unclear, a priori, whether uncertainty increases or decreases the sensitivity of yields.

Like SW (2014b) we normalize $f\left(\Theta_{\mathrm{t}}\right)$ to unity during a chosen benchmark period so that the sensitivity of yields at the ELB period can be more easily identified. In selecting the benchmark period, our first and most important criterion was that policy rates not be constrained by the ELB. SW (2014a, 2014b) chose a benchmark period in which they assumed yields responded normally to news events (1990 to 2001 for the US; and 1993 to 2006 for the UK and Germany). We maintain that in periods of uncertainty yields may still respond normally to surprise data, as long as they are not constrained. For this reason, we set $f\left(\Theta_{t}\right)$ to an average of unity when central bank policy rates are two percent or higher. The normalization to unity ensures ease of interpretation such that any value above one suggests yields are more sensitive to news than normal, and any value below one suggests yields are more constrained relative to when the ELB constraint is not in play. The two percent threshold is also a quantitative rule that prevents some arbitrariness about when the ELB is reached. ${ }^{20}$

\footnotetext{
${ }^{19}$ Equation (2) allows for time variation as explained by equation (3). However, the estimated coefficients inside the brackets in (2) are mean responses that are not time-varying. Some of the more important surprises are likely already incorporated in (3). Hence, omitting them from $\mathrm{Z}$ is intended to reduce the possibility of mis-specification. This occurred for US non-farm payroll surprises on US and Canadian 2 and 10-year yields, German and euro area 2-year yields, and Swiss 10-year yields; for US retail sales on US 2-year and 10-year yields, and French and Swedish 2year yields; for US manufacturing index on 2-year Canadian and Swiss yields; durable goods orders on 2-year Swiss and Swedish yields, and; existing home sales and consumer credit on Swiss 2-year yields.

${ }^{20}$ There are several reasons why identifying the ELB is not straightforward. Most importantly, the ELB rate differs by country. In addition, the identified ELB may change over time (refer to Table 1). Finally, since the central banks in our data set have typically adopted a two percent inflation target, the chosen threshold also has the advantage of
} 


\section{EMPIRICAL RESULTS}

\section{$\underline{\text { A Few Stylized Facts }}$}

Table 2 provides summary statistics for the pessimism, optimism and certainty variables for monetary policy committee press releases and meeting minutes (where available). The table shows how the content of central bank communications changed in the aftermath of the crisis. In general, the use of language conveying certainty increased during the post-crisis period. Interestingly, variation in content from meeting to meeting also decreased after the crisis, particularly when conveying certainty and optimism. This may reflect the fact that central bankers became more deliberate in their choice of words during crises to avoid triggering financial volatility, as well as near the ELB, in order to use changes in communication as an effective policy tool. Similarly, the use of pessimistic language did not increase in most central bank communications, as one might reasonably expect during a period of economic turmoil; but rather only did so in less than half of the communications in our sample. These stylized facts suggest that there is scope for asymmetric effects in quantifying the content of central bank statements. This possibility is especially important at the ELB, where yields may be less responsive to negative surprises than to positive surprises. ${ }^{21,22}$

[insert Table 2 around here]

Optimism and pessimism were also analyzed against economic, financial and policy indicators to get a better understanding of what the variables are capturing. In general, pessimism is

approximately capturing the dividing line between positive and negative real returns. We tested the sensitivity of this level by setting a three percent threshold on interest rates. Our results remain unchanged.

${ }^{21}$ This is somewhat of an exaggeration since negative rates are possible (see below). However, it is unclear how far below zero central banks are prepared to go.

${ }^{22}$ We performed a sensitivity analysis of the asymmetric impact of macroeconomic news surprises on yields, and found no statistically significant differences between their impacts on bond yields. 
negatively correlated with domestic GDP growth outlook, and positively correlated with the VIX and indicators of domestic and global economic policy uncertainty (Baker, Bloom and Davis 2016). These relationships align with our expectations: negative tone increases with uncertainty, financial volatility and poor economic prospects. Similarly, optimism is negatively correlated with the inflation outlook and measures of financial volatility and policy uncertainty. These relationships are generally weaker for optimism than for pessimism (correlation matrix is available in the on-line annex). The strength of these correlations suggests that the language used in central bank communications conveys data on the real economy, uncertainty and financial volatility, among other relevant information. We argue that the additional information transmitted by central bank communication includes the sentiment of the monetary policy committee about how current and future projected economic circumstances relate to the expected path of the monetary policy setting. That is, variables that evaluate the content of central bank communication are interpreted as a signal about the economy and its interaction with future policy decisions.

It is more difficult to link the 'certainty' content variable with trends in economic and financial conditions. It is possible that this sentiment captures different phenomena for each central bank. We suggest that the certainty indicator could be capturing the level of agreement on current decisions and/or the outlook for the future policy path, as well as the degree of confidence in economic projections. In addition, the stylized facts indicate that the communication of certainty has changed in form in the post-crisis periods: most central banks increased the use of language expressing certainty and decreased the variability of this language. It is plausible that the impact of this variable on financial market behaviour may also have changed in the post-crisis period. 
Figure 1 plots the 2-year (top graph) and 10-year (bottom graph) sovereign bond yields for the economies in our sample. Based on the movements in these yields it appears that 2-year yields have been relatively stable once the dramatic fall during the financial crisis is factored in, and therefore potentially constrained (if the range of yields is anything to go by). For 10-year yields, on the other hand, there has been considerable movement up to and including the beginning of 2015. Although the overall global trend is towards lower long-term yields, cross-country differences and the range of yields observed do not give the impression that they are constrained in any fashion. A crude analysis of yield movements, however, is not sufficiently informative about whether yields are constrained or whether they remain responsive to news events. Therefore, we turn to econometric estimation.

[insert Figure 2 around here]

\section{$\underline{\text { Econometric Estimates }}$}

Table 3 only includes the coefficient estimates and standard deviations on the domestic tone variables $\left(C_{t}\right)$ for the benchmark and ELB periods of the 3-month, 2-year and 10-year yields for equation (1). A case is made in the present study that how central bankers communicate their policies has a separate influence on yields, and we are interested in assessing whether this influence becomes constrained at the ELB. The other estimates are available in the on-line annex, but are not reported as they are not the focus of the analysis.

\section{[insert Table 3 around here]}

The most important observation is that the impact of the content of communication increases during the ELB period (relative to 'normal' times), both in magnitude and statistical significance. One notable exception to this pattern is that the impact of the content of $\mathrm{BoE}$ communications 
decreases at the ELB. This result is consistent with the view that central bank communication can be an important policy tool once the monetary policy interest rates approach the ELB.

Turning to the impact of content, optimism generally increases sovereign yields. During the benchmark period, optimism in BoE and Riksbank policy board meeting minutes and the ECB president's introduction to the press conference move medium-to-long term sovereign yields. Despite these effects, language conveying optimism appears to have a larger impact on yields at the ELB. This is observed for the US, Sweden, and the euro area economies. In the US, optimistic content in FOMC communications increases yields at the longer-end of the yield curve during the ELB period. Similarly, in the euro area, optimism increases short-to-medium term yields at the ELB. Optimism, however, can also have a negative impact on sovereign bond yields; this is apparent at the longer-end of the yield curve in the euro area and Canada, and along the yield curve in Sweden. Our indicator of optimism does not identify whether this is applied to future inflation or real economic growth. It is quite conceivable however, that optimism about lower inflation might lead to a reduction in sovereign yields in some economies while greater optimism about future economic growth would naturally produce the opposite result. $^{23}$

With respect to pessimistic language, higher content reduces yields during the benchmark period in the US, UK, Sweden, Switzerland and the euro area economies. Pessimistic language affects yields all along the curve, except for the US where it only effects short-term yields. At the ELB, a similar result is observed, pessimistic language appears to be able to impact both the short and

\footnotetext{
${ }^{23}$ In Canada at least the period of the ELB at the time coincided with a sharp increase in energy prices which may have played a factor in the Bank of Canada abandoning its conditional commitment a couple of months before forward guidance was due to expire. In Sweden it was rising housing prices that led the Riksbank to raise the policy rate, only to reverse its decision later.
} 
long end of the yield curve. Generally, pessimism has a negative impact on long-term yields, as observed for US FOMC minutes and Riksbank communications. This undoubtedly reflects the negative effect of a downgrade in the economic outlook. At the short-end of the yield curve, pessimistic language has a positive effect, as observed in the US and Canada. This likely captures the connection between pessimism and perceived risk suggested earlier (also see the online annex). In the euro area economies, pessimism has a positive impact along the yield curve at the ELB; this is a plausible reaction to heightened uncertainty about the future of the Economic and Monetary Union. Importantly, our results suggest that yields can be just as responsive to negative shocks as positive shocks in the content of central bank communication when policy rates are near the ELB.

Looking at the impact of certainty clearly shows how the impact of content can change over time. The sentiment of certainty decreases yields in the UK, Switzerland and the euro area in the benchmark period. During this period, certainty may have transmitted to market behaviour through the risk channel. That is, an increase in content of language expressing certainty, could lead to a decrease in perceived risk, or in uncertainty in future policy decisions or the economic outlook. During the ELB period, however, certainty has a positive impact in the UK, US, Sweden, and euro area economies. Apart from Sweden, the impact appears to be larger on the short-to-medium end of the yield curve. This may reflect more certainty in the economic outlook which signals that a change in monetary policy stance will occur in the near-term.

Turning briefly to spillovers, magnitudes of the impact of the content of US FOMC communication increased yields in the euro area at the ELB, but decreased UK gilt yields. In all other countries, the impact of the content of FOMC statements and meeting minutes remains similar to the benchmark period. Generally, greater optimism in FOMC communications 
increased yields, and pessimism decreased yields except for a few instances where it increased yields on short-term bonds. Certainty is shown to have decreased yields in the euro area economies, while increasing yields in Canada and Sweden. For Canada and Sweden the greater certainty emanating from the US could reflect higher future real economic growth. The US, of course, is Canada's largest trading partner by far. An explanation for the euro area response is less obvious; good economic news for the US may have been interpreted as bad news for the euro area which was still in the midst of the sovereign debt crisis while the US was emerging from its own financial crisis. Finally, the content of ECB press conferences is not found to have any notable spillovers to Sweden or Switzerland at the ELB.

Next, we examine the estimates based on equation (2). In addition to being based on a non-linear functional form, the specification permits us to evaluate the time-varying sensitivity of yieldsconditional on both market and central bank news - to two forms of market uncertainty and the level of the yield, as previously defined (see equations (2) and (3)). Figure 2 plots estimates of the time-varying sensitivity of 2- and 10-year yields to changing uncertainty. The Figure is subdivided into two parts. Part (a) plots the sensitivity indicator for 2-year yields on the left and for the 10-year yields on the right for the US, the euro area, the UK and Switzerland. The same structure is used in Figure 2(b) where data for France, Germany, Canada and Sweden are plotted. Table 4 provides the numerical average of the sensitivity of yields, that is, $f\left(\Theta_{t}\right)$, during the ELB period; as it is set to unity during the benchmark period. A value below one represents a decrease in sensitivity to news and a value of zero indicates that an asset price is fully constrained.

[insert Figure 3 around here]

Paralleling the results found in SW (2014b), we see that the sensitivity of two-year US Treasuries dropped as the financial crisis developed (top left corner of Figure 2(a)). By 2012, the 
two-year yields in all the countries in the sample except Switzerland became constrained or unresponsive to news events. Indeed, during the ELB period for each country (defined in Table 1), yield sensitivity $\left(f\left(\Theta_{\mathrm{t}}\right)\right)$ is reduced to a range of 0.03 in France to 0.49 in Canada and Sweden. On the other hand, the 10-year yields generally became more responsive to news events during the crisis. While some 10-year sovereign bond yields became constrained over time, others remained responsive to news through most of the crisis. And indeed, while some longterm sovereign yields are clearly restrained during the ELB period (including the euro area, France, and Switzerland), other sovereign yields may have become more responsive to news, including Sweden and the UK.

In addition, some 10-year yields, though less sensitive, appear to remain somewhat responsive to news, including the US, Canada and Germany. This may be related to the fact that these are safe and heavily-traded assets. Canada is an interesting case because bond yields remained less responsive to news even after the policy rate was lifted from the ELB in mid-2010. These results reveal how yields can be constrained, or at least less responsive to news, even when policy rates are not at the ELB (i.e., Canada), while they may also remain sensitive at the ELB in some circumstances, particularly for longer-term yields (i.e., US and UK). ${ }^{24}$

The long-term yields in the European countries (Figure 2(b)) appear to be much more sensitive to news events after the crisis than in Canada and the United States, as well as the UK. This may be due to the possibility that these yields became more vulnerable to uncertainty as the euro area crisis evolved. This argument is further underscored by the fact that yield sensitivity declined for these yields after key policy events in the euro area such as the securities market program (SMP)

\footnotetext{
${ }^{24}$ In a similar analysis applied to exchange rates, Lombardi, Siklos and St. Amand (2016) find that the exchange rates of small-open economies (Canadian dollar and Swedish krona) remain highly responsive to news event at the ZLB. Although yields are constrained, the exchange rate mechanism may still act as an effective shock absorber.
} 
announced in May 2010 and the passages of the fourth and fifth Greek austerity packages by narrow margins in June and October 2011.

Another interesting pattern, although with too few observations to make a firm conclusion, is that the announcement of negative interest rates in Sweden in February 2015 and in Switzerland in December 2014, appear to have increased the sensitivity of yields. Similarly, short-term yields in the euro area became more sensitive to news when the ECB introduced extraordinary UMP measures in early 2015. Due to the limited sample size for the period when policy rates are negative and the ECB was engaged in a full-scale sovereign bond purchase program, it is of course difficult to reach a definite conclusion about the change in the responsiveness of yields owing to these events.

\section{CONCLUSIONS}

This paper has empirically considered the potential constraint that the ELB poses for central banks seeking to retain the effectiveness of monetary policy. We examine the responsiveness of yields across the term structure of sovereign bonds to news in eight economies where nominal policy rates hit the ELB following the international financial crisis of 2007-9.

Using a version of the methodology recently implemented by SW (2014a, 2014b), we extend their approach to analyze the impact of the content of central bank communications, in addition to the news content of various UMPs and macroeconomic data releases, on the term structure of interest rates. We also explicitly allow for cross-country spillovers from the US and the euro area.

We find that most medium- to longer-term yields become constrained around 2012approximately three years after most central banks approached the ELB. There are, however, 
some notable exceptions, including 10-year government bond yields in Sweden, the US and the UK, which were only slightly less responsive to news relative to a benchmark period when their 'news response' was deemed to be normal (i.e., consistent with pre-crisis types of responses). For example, Canada's record illustrates that yields can be constrained even if the policy rate has lifted off from the ELB. Since Canada is a small-open economy whose economic fortunes are closely tied to the US, our findings also suggest that spillover effects, which we consider but SW (2014a, 2014b) did not, may also play a role in the data dependence of yields. There is also early evidence that yields may once again become responsive to news events even when the zero boundary has been breached, as it was in Sweden at the beginning of 2015. For small-open economies, the other variable that is ignored in our analysis is the exchange rate which no doubt also influences some of our findings.

A general reduction in the sensitivity of yields need not, however, imply that monetary policy becomes less effective. We conclude that sovereign bond yields become more sensitive to the content of central bank communications for longer maturities after the policy rate reached the ELB. This suggests that monetary policy remains an effective tool at least for a period of time even after the ELB is reached, as longer-term sovereign bond yields are not immediately constrained by the ELB. Nevertheless, it is also likely that it will be more difficult for central banks to maintain the effectiveness of monetary policy since, as demonstrated in this paper, the responsiveness of asset prices will likely eventually taper off.

Our empirical analysis can be extended in a number of directions. First, optimism, pessimism and certainty are not the only sentiments that can be extracted from verbal or written forms of central bank communication. Next, for small-open economies, interest rate and exchange rates are jointly determined. Since news can affect both, there is scope for a more sophisticated 
analysis of the kind conducted here. Finally, if central banks ever return to 'normal' interest rates we could then investigate whether a 'new normal' has emerged in how yields across the term structure respond to news from various sources and whether the resulting spillovers would also change. All of these ideas are left for future research. 


\section{References}

Amirault, D. and B. O’Reilly. "The Zero Lower Bound on Nominal Interest Rates: How Important Is It?” Bank of Canada Working Paper, 2001-6, April 2001.

Armstrong, J. S. "Combining Forecasts" in Principles of Forecasting: A Handbook for Researchers and Practitioners, edited by J. S. Armostrong. Norwell, Mass.: Kluwer Academic Publishers, 2001, 1-19.

Baker, S. R., N. Bloom, and S. J. Davis. "Measuring Economic Policy Uncertainty." Data accessed on 21 July 2016.

Ball, L., J. Gagnon, P. Honohan, and S. Krogstrup. What Else Can Central Bank Do? Geneva Reports on the World Economy, 18, September 2016.

Bernanke, B. S. "Monetary Policy since the Onset of the Crisis." Speech delivered at the Federal Reserve Bank of Kansas City Economic Symposium, Jackson Hole, Wyoming, 31 August 2012.

Bernanke, B., V. Reinhart and B. Sack. "Monetary Policy Alternatives at the Zero Lower Bound.” Brookings Paper on Economic Activity, 2, 2004, 1-100.

Blinder, A. S. "Summary Panel - Monetary Policy at the Zero Lower Bound: Balancing the Risks.” Journal of Money, Credit and Banking, 32(2), November 2000.

Blinder, A., M. Ehrmann, M. Fratzscher, J. De Haan and D.-J. Jansen. “Central Bank Communication and Monetary Policy: A Survey of Theory and Evidence.” NBER Working Paper Series, 13932, 2008.

Buiter, W. H. "Negative Nominal Interest Rates: Three Ways to Overcome the Zero Lower Bound.” North American Journal of Economics and Finance, 20(3), 2009, 213-38.

Carney, M. "Monetary Policy After the Fall.” Speech delivered at the Eric J. Hanson Memorial Lecture, University of Alberta, Edmonton, 1 May 2013.

Chung, H., J-P. Laforte, D. Reifschneider, and J. C. Williams. "Underestimated the Likelihood and Severity of Zero Lower Bound Events.” Journal of Money, Credit and Banking, 44(1), 2012, 47-82.

Christensen, J., and G. Rudebusch. “The Response of Interest Rates to US and UK Quantitative Easing.” Economic Journal, 122, 2012, F385-F414.

Davis, J. S., and M. A. Wynne. “Central Bank Communications: A Case Study.” Federal Reserve Bank of Dallas Globalization and Monetary Policy Institute Working Paper, 283, 2016.

Danker, D. J., and M. M. Luecke “Background on FOMC Meeting Minutes.” Federal Reserve Bulletin, Spring 2005, 175-179.

De Carvalho, C. V., E. Hsu, and F. Nechio. "Fed Communication and the Zero Lower Bound.” FRBSF Economic Letter, 21, July, 2016. 
De Rezende, R., D. Kjellberg, and O. Tysklind. "Effects of the Riksbank’s Government Bond Purchases on Financial Prices.” Economic Commentaries 13, Sveriges Riksbank, 2015.

ECB. “The New Euro Area Yield Curves.” ECB Monthly Bulletin, 2008, February.

Ehrmann, M., and M. Fratzscher. "Communication by Central Bank Committee Members: Different Strategies, Same Effectiveness?” Journal of Money, Credit and Banking, 39(2/3), 2007, 509-41.

Filardo, A., and B. Hofmann. "Forward Guidance at the Zero Lower Bound.” BIS Quarterly Review, March, 2014, 37-54.

Fratzscher, M., M. Lo Duca, and R. Straub. "On the international spillovers of US Quantitative Easing.” The Economic Journal, forthcoming.

Gagnon, J. "Quantitative Easing: An Underappreciated Success." Peterson Institute for International Economics Policy Brief, April 2016, PB16-4.

Gagnon, J., M. Raskin, J. Remache, and B. Sack. "The Financial Market Effects of the Federal Reserve's Large-Scale Asset Purchases.” International Journal of Central Banking, 7(1), 2011, 3-43.

Gerlach, S. "Interest Rate Setting by the ECB, 1999-2006: Words and Deed.” International Journal of Central Banking, 3(3), 2007, 1-45.

Gilchrist, S., D. López-Salido, and E. Zkrajšek. "Monetary Policy and Real Borrowing Costs at the Zero Lower Bound.” FEDS, 39(May), 2014.

Goodfriend, M. “Overcoming the Zero Lower Bound on Interest Rate Policy.” Journal of Money, Credit and Banking, 32(4:2), 2000, 1007-35.

Gürkaynak, R., B. Sack, and E. Swanson. "The Sensitivity of Long-Term Interest Rates to Economic News: Evidence and Implications.” American Economic Review, 95(1), 2005a, 42636.

Gürkaynak, R., B. Sack and E. Swanson. "Do Actions Speak Louder Than Words? The Response of Asset Prices to Monetary Policy Actions and Statements.” International Journal of Central Banking, 1(1), 2005b, 55-93.

Hart, R.P., J. P. Childers, and C.J. Lind. Political Tone: How Leaders Talk and Why. Chicago: University of Chicago Press, 2013.

He, Z. "Evaluating the Effect of the Bank of Canada's Conditional Commitment Policy." Discussion Paper, 11, 2010.

Jansen, D.-J., and J. De Haan. "Has ECB communication been helpful in predicting interest rate decisions? An evaluation of the early years of the Economic and Monetary Union." Applied Economics, 41(16), 2010, 1995-2003. 
Joyce, M., A. Lasaosa, I. Stevens, and M. Tong. “The Financial Market Impact of Quantitative Easing in the United Kingdom.” International Journal of Central Banking, 7(3), 2011, 113-161.

Krishnamurthy, A., and Vissing-Jorgensen, A. "The Effects of Quantitative Easing on Interest Rates: Channels and Implications for Policy.” Brookings Papers on Economic Activity, Fall, 2011, 215-87.

Kuttner, K. "Monetary Policy Surprises and Interest Rates: Evidence from the Fed Funds Futures Market.” Journal of Monetary Economics, 47(3), 2001, 523-44.

Kuttner, K., and A. Posen. "The Difficulty of Discerning What's Too Tight? Taylor Rules and Japanese Monetary Policy.” North American Journal of Economics and Finance, 15(1), 2004, $53-74$.

Levin, A., D. López-Salido, E. Nelson, and T. Yun. "Limitations on the Effectiveness of Forward Guidance at the Zero Lower Bound." International Journal of Central Banking, 6(1), 2010, 143-89.

Lombardi, D., P. L. Siklos, and S. St. Amand. "Exchange rates, central bank news and the zero lower bound.” Applied Economics Letters, 24(4), 2016, 269-72.

Loughran, T., and B. McDonald. "When Is A Liability Not a Liability? Textual analysis, Dictionaries, and 10-Ks.” Journal of Finance, 66(1), 2011, 35-65.

MacKinlay, A. C. "Event Studies in Economics and Finance.” Journal of Economic Literature, 35(March), 1997, 13-39.

McCallum, B. "Theoretical Analysis Regarding a Zero Lower Bound on Nominal Interest Rates.” NBER Working Paper, 7677, 2000.

Meade, E. E. “The FOMC: Preferences, Voting, and Consensus.” Federal Reserve Bank of St. Louis Review, March/April(1), 2005, 93-102.

Meade, E.E., N. A. Burk, and M. Josselyn. "The FOMC Meeting Minutes: As Assessment of Counting Words and the Diversity of Views.” FEDS Notes, 2015, 26 May.

Riboni, A., and F. Ruge-Marcia. "Dissent in monetary policy decisions”, Journal of Monetary Economics, 66, 2014, 137-54.

Rogers, John H., Chiara Scotti, and Jonathan H. Wright, "Evaluating Asset-Market Effects of Unconventional Monetary Policy: A Cross-Country Comparison.” International Finance Discussion Papers, 1101, 2014.

Romer, C. and D. Romer. "A new Measure of Monetary Policy Shocks: Derivation and Implications.” American Economic Review, 94(September), 2004, 1055-1084.

Romer, C. and D. Romer. "Does Monetary Policy Matter? A New Test in the Spirit of Friedman and Schwartz," in NBER Macroeconomic Annual 1989, Volume 4, edited by O. J. Blanchard, and S. Fischer. Cambridge, MA: National Bureau of Economic Research, 1989, 121-184. 
Siklos, P. and A. Spence. "Faceoff: Should the Bank of Canada Release its Projections of the Interest Rate Path? - The Cases for and Against.” C.D. Howe Institute Commentary, October, 2010.

Siklos, P. L. "Sources of Disagreement in Inflation Forecasts: An International Empirical Investigation.” Journal of International Economics, 90, May 2013, 218-231.

Sims, C.” Implications of Rational Inattention.” Journal of Monetary Economics, 50(April), 2003, 665-690.

Summers, L. "Panel Discussion: How Should Long-Term Monetary Policy Be Determined?" Journal of Money, Credit and Banking 23(3), 1991, 625-31.

Svensson, L. E. O. "Monetary Policy and Financial Markets at the Effective Lower Bound." Journal of Money, Credit and Banking, 42(s1), 2010, 229-42.

Svensson, L. E. O. "Estimating and Interpreting Forward Interest Rates: Sweden 1992-1994.” NBER Working Paper, 4871, 1994.

Swanson, E. and J. C. Williams. "Measuring the Effect of the Zero Lower Bound on Yields and Exchange Rates in the U.K. and Germany." Federal Reserve Bank of San Francisco working paper 2013-21, August, 2014a.

Swanson, E. and J. C. Williams. "Measuring the Effect of the Zero Lower Bound on Medium and Longer-Term Interest Rates.” American Economic Review, 104(October), 2014b, 3154-85.

Tsay, R. Analysis of Financial Time Series. New York: John Wiley \& Sons, Third Edition, 2010.

Ueda, K. “The Bank of Japan's Struggle in the Zero Lower Bound on Nominal Interest Rates: Exercises in Expectations Management.” Working Paper, University of Tokyo, September, 2005.

Wiederholt, M. "Dispersed Inflation Expectations and the Zero Lower Bound”, Working Paper, Northwestern University, February, 2012.

Winkelmann, L., M. Bibinger and T. Linzert "ECB Monetary Policy Surprises: Identification Through Cojumps in Interest Rates”, Journal of Applied Econometrics, 31(4), 2016, 613-29.

Woodford, M. "Methods of Policy Accommodation at the Interest-Rate Lower bound", in The Changing Policy Landscape Federal Reserve Bank of Kansas City Economic Policy Symposium. Kansas City: Federal Reserve Bank of Kansas City, 2012, 185-288.

Yellen, J. L. "Monetary Policy and Economic Recovery." Speech delivered at the Economic Club of New York, New York, 16 April 2014. 
TABLE 1

\begin{tabular}{|c|c|c|c|}
\hline \multicolumn{4}{|c|}{ How The Effective Lower Bound is Defined in Different Economies } \\
\hline Economy & $\begin{array}{l}\text { ELB Sample } \\
\text { Period }\end{array}$ & ELB Rate $^{2}$ & Notes \\
\hline Canada & $\begin{array}{l}21 \text { Apr } 2009 \text { to } \\
31 \text { May } 2010\end{array}$ & $\begin{array}{l}\text { During the } \\
\text { 2009-2010, the } \\
\text { ELB was } \\
\text { deemed to be } \\
\text { 0.25\%; } \\
-0.50 \% \text { revised } \\
\text { ELB target } \\
\text { overnight } \\
\text { lending rate }\end{array}$ & $\begin{array}{l}\text { The Press Release of the interest rate announcement } \\
\text { stated that the Bank judges } 0.25 \% \text { to be the ELB. } \\
\text { Revised in December } 2015 \text { to }-0.50 \% \text { (Bank of } \\
\text { Canada 2015). }\end{array}$ \\
\hline
\end{tabular}

\begin{tabular}{|c|c|c|c|}
\hline $\begin{array}{l}\text { EMU (euro } \\
\text { area) }\end{array}$ & $\begin{array}{l}4 \text { July } 2014 \text { to } \\
31 \text { March } 2015^{1}\end{array}$ & $\begin{array}{l}0 \% \text { target } \\
\text { MRO }\end{array}$ & $\begin{array}{l}\text { Decreased marginal refinancing operations (MRO) } \\
\text { rate to } 0.15 \% \text { on } 4 \text { June 2014, which Draghi indicated } \\
\text { "for all practical purposes, we have reached the lower } \\
\text { bound" but indicating further adjustments are } \\
\text { possible. The target marginal refinancing rate was } \\
\text { decreased further in September } 2014 \text { and December } \\
\text { 2015; and lowered to 0\% in March 2016. It remains } \\
\text { unclear what the ELB is. }\end{array}$ \\
\hline Switzerland & $\begin{array}{l}3 \text { August } 2011 \\
\text { to } 31 \text { March } \\
2015^{1}\end{array}$ & $\begin{array}{l}-1.25 \text { to } 0.25 \\
\text { target range } \\
\text { for the } 3- \\
\text { month Libor }\end{array}$ & $\begin{array}{l}\text { The Libor rate was } 0.00 \text { to } 0.25 \text { (aiming for as close } \\
\text { to zero as possible) between } 3 \text { Aug } 2011 \text { and } 17 \text { Dec } \\
2014 \text {. Then it was lowered to }-0.75 \text { to } 0.25 \text {, aiming } \\
\text { for negative territory on the } 3 \text {-month Libor from } 18 \\
\text { Dec } 2014 \text { to } 14 \text { Jan } 2015 \text {. On } 15 \text { January } 2015 \text { it was } \\
\text { further lowered to }-1.25 \text { to }-0.25 \text {. }\end{array}$ \\
\hline $\begin{array}{l}\text { United } \\
\text { Kingdom }\end{array}$ & $\begin{array}{l}5 \text { Mar } 2009 \text { to } \\
31 \text { March } 2015^{1}\end{array}$ & $\begin{array}{l}0.5 \% \text { target } \\
\text { bank rate to } \\
\text { present }\end{array}$ & \\
\hline $\begin{array}{l}\text { United } \\
\text { States }\end{array}$ & $\begin{array}{l}16 \text { December } \\
2008 \text { to } 31 \\
\text { March } 2015^{1}\end{array}$ & $\begin{array}{l}0.00 \text { to } 0.25 \\
\text { target range } \\
\text { for the federal } \\
\text { funds rate }\end{array}$ & \\
\hline
\end{tabular}

July 22009 to

$\begin{array}{lll}\text { Sweden } & \text { June } 302010 ; 9 & -0.50 \% \text { repo } \\ & \text { July 2014 to } 31 & \text { rate } \\ & \text { March } 2015^{1}\end{array}$

Sources: Central banks.

1. The ELB end date of 31 March 2015 represents the end of the sample period of the analysis;

2. As of February 2017.
The policy rate was 0.25 percent from 2 July 2009 to 30 June 2010. It was lowered back to 0.25 in 9 July 2014 followed by further cuts. Note that the Riksbank never stated that 0.25 was the zero lower, in fact the committee meeting minutes indicate that they did not believe the ZLB was static and it could in fact be negative. 
TABLE 2

Agreement, Optimism and Sentiment in Monetary Policy Communication

Source

\begin{tabular}{cc}
\multicolumn{2}{c}{$\begin{array}{c}\text { Certainty } \\
\text { Pre- }\end{array}$} \\
Prisis & Prisis \\
3.97 & 4.13 \\
$(1.20)$ & $(1.16)$ \\
$3.50^{*}$ & $4.08^{*}$ \\
$(0.80)$ & $(0.76)$ \\
3.51 & 3.12 \\
$(1.09)$ & $(1.15)$ \\
$0.58^{*}$ & $1.75^{*}$ \\
$(0.89)$ & $(0.36)$ \\
2.15 & 2.73 \\
$(1.88)$ & $(1.55)$ \\
$7.89^{*}$ & $8.88^{*}$ \\
$(2.47)$ & $(2.11)$ \\
$1.12^{*}$ & $1.77^{*}$ \\
$(0.59)$ & $(0.67)$ \\
$3.94^{*}$ & $7.80^{*}$ \\
$(1.94)$ & $(1.66)$ \\
$2.23^{*}$ & $3.06^{*}$ \\
$(0.80)$ & $(0.44)$
\end{tabular}

Optimism

Pre- Post-

Crisis Crisis

1.67* 2.49*

$(0.81) \quad(0.74)$

$2.67 \quad 2.86$

$(0.71) \quad(0.49)$

$1.12 * \quad 1.56 *$

Pessimism

Bank of Canada Press Release

ECB Introductory statement to the Press

Conference

Swedish Riksbank Press Release

Swedish Riksbank Minutes of the

Monetary Policy Meeting

Swiss National Bank Monetary Policy

Assessment

Bank of England Press release

Bank of England Minutes of the

Monetary Policy Committee Meeting

US FOMC Press Monetary Policy

Statement

$(0.49) \quad(0.67)$

1.38* $1.53^{*}$

Pre-

Crisis

1.32* 2.36*

US FOMC meeting minutes

$(0.27)$

(0.24)

$(0.74)$

1.34*

(0.79)

(0.45)

$1.65^{*}$

$\quad(0.55)$

$1.34 \quad 1.63$

$\begin{array}{ll}(0.68) & (0.82)\end{array}$

$1.32 \quad 1.11$

1.81

1.75

$(0.62)$

(0.40)

$(0.47)$

(0.34)

1.15

1.08

1.46*

2.14*

$(0.56)$

(0.98)

(0.78)

$0.95 *$

(0.37)

1.63

1.16

$1.26 *$

(0.92)

(1.10)

$\begin{array}{llll}(0.21) & (0.31) & (0.48) & (0.48)\end{array}$

Source: Authors' calculations.

$1.87 \quad 2.22$

(1.06) (0.59)

1.67

1.66

1.99*

$1.64^{*}$

(1.02)

(0.87)

(0.42)

$(0.32)$

1.98

1.75

Notes: Values represent the number of positive or negative words as a percentage of the total word count. * represents statistically significant difference in means in pre- and post-crisis periods at the 99\% confidence level. Standard deviations are in parenthesis. Pre-crisis period is 1 January 2001 to 30 September 2008; post-crisis period is 1 October 2008 to 31 March 2015. 
FIGURE 1

Sovereign Bond Yields (January 2001 to March 2015)
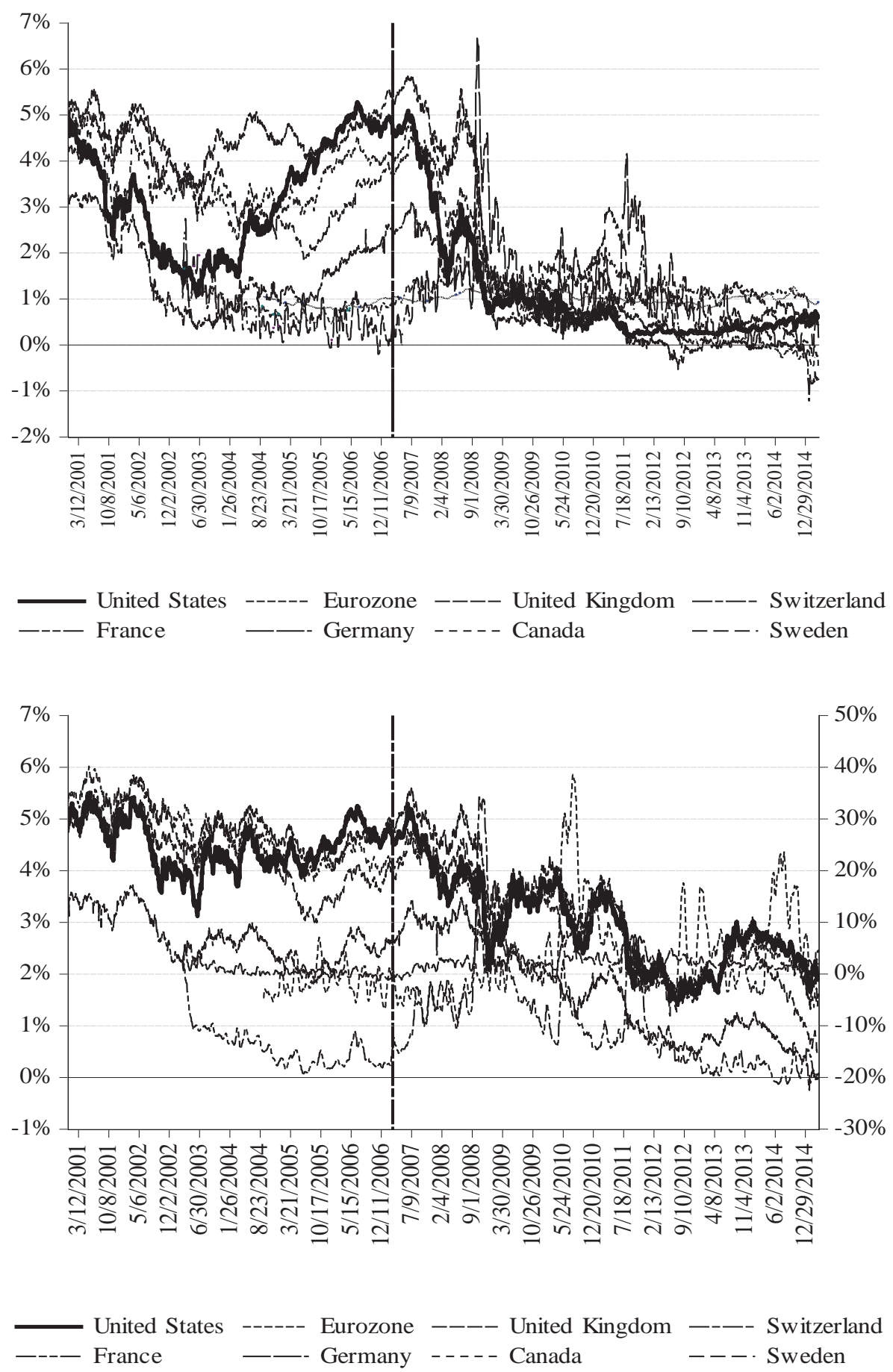

Source: Thomson Reuters Datastream.

Notes: The yields on the upper figure are 2-year yield to maturity; the data on the lower figure are 10-year yield to maturity government bond yields. The vertical line indicates the start of the so-called 'Global Financial Crisis' (2/27/2007) according to the St. Louis Federal Reserve's timeline of the financial crisis. 
TABLE 3

Results from Equation 1 (Benchmark and ELB Period)

a) United States

\begin{tabular}{lcccccc} 
& \multicolumn{3}{c}{ Benchmark } & & \multicolumn{2}{c}{ ELB } \\
& 3-month & 2 -year & 10 -year & 3-month & 2-year & 10 -year \\
\hline \multirow{2}{*}{ FOMC Press Release Certainty } & -4.79 & 0.22 & 0.52 & -0.03 & 0.02 & 0.20 \\
& $(2.96)$ & $(2.55)$ & $(1.94)$ & $(0.25)$ & $(0.78)$ & $(1.59)$ \\
\hline \multirow{2}{*}{ FOMC Press Release Optimism } & 2.57 & 1.47 & -0.04 & 0.34 & $2.51^{* *}$ & $4.72^{* *}$ \\
& $(1.82)$ & $(1.76)$ & $(1.14)$ & $(0.25)$ & $(1.13)$ & $(2.28)$ \\
\hline \multirow{2}{*}{ FOMC Press Release Pessimism } & $-4.04^{* * *}$ & 0.01 & 0.11 & 0.10 & 0.61 & 0.72 \\
& $(1.33)$ & $(1.18)$ & $(0.95)$ & $(0.19)$ & $(0.98)$ & $(1.90)$ \\
\hline \multirow{2}{*}{ FOMC Minutes Certainty } & -0.30 & 0.64 & 0.33 & $0.72^{* *}$ & $1.50^{* *}$ & 1.19 \\
& $(1.53)$ & $(1.37)$ & $(1.28)$ & $(0.28)$ & $(0.70)$ & $(1.13)$ \\
\hline \multirow{2}{*}{ FOMC Minutes Optimism } & 1.10 & 0.53 & 1.41 & -0.14 & $1.12^{*}$ & 1.48 \\
& $(0.94)$ & $(1.19)$ & $(0.99)$ & $(0.33)$ & $(0.59)$ & $(0.99)$ \\
\hline \multirow{2}{*}{ FOMC Minutes Pessimism } & 0.66 & 0.95 & $1.63^{*}$ & $0.55^{*}$ & 0.33 & $-1.91^{* *}$ \\
& $(1.68)$ & $(1.08)$ & $(0.96)$ & $(0.32)$ & $(0.58)$ & $(0.87)$ \\
\hline \multirow{2}{*}{$\mathrm{N}$} & 645 & 646 & 646 & 935 & 935 & 935
\end{tabular}

b) United Kingdom

\begin{tabular}{lcccccc} 
& 3-month & 2-year & 10 -year & 3-month & 2-year & 10 -year \\
\hline \multirow{2}{*}{ BoE Press Release Certainty } & 0.22 & $-1.49^{*}$ & -0.75 & $0.43^{* * *}$ & 0.08 & 0.12 \\
& $(0.29)$ & $(0.83)$ & $(0.62)$ & $(0.16)$ & $(0.81)$ & $(1.34)$ \\
\hline \multirow{2}{*}{ BoE Press Release Optimism } & 0.96 & 2.53 & 1.75 & -0.21 & -0.43 & 1.86 \\
& $(0.67)$ & $(1.60)$ & $(1.21)$ & $(0.20)$ & $(1.47)$ & $(2.65)$ \\
\hline \multirow{2}{*}{ BoE Press Release Pessimism } & $-3.61^{* * *}$ & $-5.04^{* * *}$ & $-2.15^{* *}$ & $-0.51^{* *}$ & 0.20 & -1.45 \\
& $(0.63)$ & $(1.25)$ & $(1.04)$ & $(0.21)$ & $(0.83)$ & $(1.44)$ \\
\hline \multirow{2}{*}{ BoE Minutes Certainty } & $-1.07^{*}$ & -0.56 & -0.57 & 0.03 & 0.50 & 0.66 \\
& $(0.55)$ & $(0.79)$ & $(0.62)$ & $(0.08)$ & $(0.42)$ & $(0.65)$ \\
\hline \multirow{2}{*}{ BoE Minutes Optimism } & 1.13 & $2.47^{* *}$ & $1.89^{* *}$ & -0.03 & -0.33 & -0.33 \\
& $(0.75)$ & $(1.06)$ & $(0.80)$ & $(0.08)$ & $(0.56)$ & $(0.71)$ \\
\hline \multirow{2}{*}{ BoE Minutes Pessimism } & $-0.88^{* *}$ & $-1.59^{* *}$ & $-1.62^{* * *}$ & 0.02 & -0.06 & -0.83 \\
& $(0.40)$ & $(0.71)$ & $(0.54)$ & $(0.07)$ & $(0.44)$ & $(0.68)$ \\
\hline $\mathrm{N}$ & 920 & 920 & 920 & 1,018 & 1,018 & 1,018
\end{tabular}

c) Canada

\begin{tabular}{lcccccc} 
& 3-month & 2-year & 10 -year & 3-month & 2-year & 10 -year \\
\hline \multirow{2}{*}{ BoC Press Release Certainty } & -0.22 & 0.40 & 0.19 & -1.24 & -0.97 & 1.89 \\
& $(0.83)$ & $(0.92)$ & $(0.56)$ & $(0.83)$ & $(1.86)$ & $(1.17)$ \\
\hline \multirow{2}{*}{ BoC Press Release Optimism } & 1.59 & 1.39 & -0.01 & 1.29 & -0.86 & $-2.18^{* *}$ \\
& $(1.10)$ & $(1.07)$ & $(0.58)$ & $(1.13)$ & $(1.90)$ & $(1.08)$ \\
\hline \multirow{2}{*}{ BoC Press Release Pessimism } & -0.90 & -0.98 & 0.19 & $10.21^{* *}$ & 10.33 & -0.45 \\
& $(1.05)$ & $(1.04)$ & $(0.69)$ & $(4.23)$ & $(6.95)$ & $(5.34)$ \\
\hline $\mathrm{N}$ & 1,101 & 1,102 & 1,102 & 155 & 155 & 155
\end{tabular}

\section{d) euro area}

\begin{tabular}{lcccccc} 
& 3-month & 2-year & 10 -year & 3-month & 2-year & 10 -year \\
\hline ECB Introduction to the Press & $-0.86^{*}$ & -0.61 & -0.18 & $1.63^{* * *}$ & -0.62 & $5.83^{*}$ \\
Conference Certainty & $(0.51)$ & $(1.03)$ & $(0.46)$ & $(0.54)$ & $(0.53)$ & $(3.22)$ \\
\hline ECB Introduction to the Press & 0.17 & 0.15 & $0.99^{*}$ & 1.74 & $2.62^{* *}$ & -5.52 \\
Conference Optimism & $(0.58)$ & $(0.80)$ & $(0.58)$ & $(1.46)$ & $(1.06)$ & $(4.96)$ \\
\hline ECB Introduction to the Press & -0.17 & $-1.27^{*}$ & -0.53 & 0.89 & $1.66^{* * *}$ & -2.88 \\
Conference Pessimism & $(0.64)$ & $(0.74)$ & $(0.40)$ & $(0.57)$ & $(0.59)$ & $(3.65)$ \\
\hline $\mathrm{N}$ & 667 & 667 & 667 & 104 & 104 & 104
\end{tabular}




\section{e) Germany}

\begin{tabular}{lcccccc} 
& \multicolumn{3}{c}{ Benchmark } & \multicolumn{2}{c}{ ELB } \\
& 3-month & 2-year & 10-year & 3-month & 2-year & 10 -year \\
\hline ECB Introduction to the Press & -1.11 & -1.06 & -0.11 & -0.08 & 0.08 & -0.33 \\
Conference Certainty & $(1.01)$ & $(1.04)$ & $(0.55)$ & $(0.54)$ & $(0.42)$ & $(1.47)$ \\
\hline ECB Introduction to the Press & -1.55 & -0.49 & -0.11 & $4.32^{* * *}$ & 1.40 & $-4.83^{* *}$ \\
Conference Optimism & $(1.01)$ & $(0.75)$ & $(0.57)$ & $(1.62)$ & $(1.30)$ & $(2.24)$ \\
\hline ECB Introduction to the Press & $-1.60^{*}$ & $-1.43^{*}$ & $-1.26^{* * *}$ & $3.34^{* * *}$ & 0.52 & $4.62^{* *}$ \\
Conference Pessimism & $(0.91)$ & $(0.75)$ & $(0.41)$ & $(1.13)$ & $(0.65)$ & $(2.17)$ \\
\hline $\mathrm{N}$ & 964 & 964 & 110 & 110 & 110 & 964
\end{tabular}

\section{f) France}

\begin{tabular}{lcccccc} 
& 3-month & 2-year & 10 -year & 3 -month & 2-year & 10 -year \\
\hline ECB Introduction to the Press & -0.62 & -0.62 & -0.41 & $2.99^{* * *}$ & $0.67^{* *}$ & $1.90^{*}$ \\
Conference Certainty & $(0.49)$ & $(0.84)$ & $(0.68)$ & $(0.50)$ & $(0.27)$ & $(1.06)$ \\
\hline ECB Introduction to the Press & -0.31 & -0.94 & -0.86 & $5.24^{* * *}$ & $1.04^{* * *}$ & 0.81 \\
Conference Optimism & $(0.49)$ & $(0.82)$ & $(0.68)$ & $(0.30)$ & $(0.36)$ & $(0.69)$ \\
\hline ECB Introduction to the Press & $-0.95^{* *}$ & $-2.09^{* *}$ & $-1.82^{* *}$ & $6.15^{* * *}$ & $2.40^{* * *}$ & $5.10^{* * *}$ \\
Conference Pessimism & $(0.39)$ & $(1.02)$ & $(0.71)$ & $(0.74)$ & $(0.46)$ & $(1.40)$ \\
\hline $\mathrm{N}$ & 946 & 946 & 946 & 104 & 104 & 104
\end{tabular}

\section{g) Sweden}

\begin{tabular}{lcccccc} 
& 3-month & 2-year & 10-year & 3-month & 2-year & 10 -year \\
\hline \multirow{2}{*}{ Riksbank Press Release Certainty } & 1.53 & 0.66 & -1.46 & -0.24 & 3.04 & $3.94 * * *$ \\
& $(1.63)$ & $(1.39)$ & $(0.96)$ & $(1.05)$ & $(1.87)$ & $(1.37)$ \\
\hline \multirow{2}{*}{ Riksbank Press Release Optimism } & -0.03 & -0.99 & -0.35 & $-1.71^{*}$ & $-4.39 * * *$ & $-4.19^{* * *}$ \\
& $(1.55)$ & $(1.77)$ & $(1.36)$ & $(1.02)$ & $(1.60)$ & $(1.20)$ \\
\hline \multirow{2}{*}{ Riksbank Press Release Pessimism } & $-4.07 *$ & -2.02 & -0.55 & $-4.27 * * *$ & -0.86 & $-4.26^{* *}$ \\
& $(2.35)$ & $(1.65)$ & $(1.12)$ & $(1.54)$ & $(2.27)$ & $(1.97)$ \\
\hline \multirow{2}{*}{ Riksbank Minutes Certainty } & 0.24 & 0.17 & 0.69 & -0.21 & -0.36 & 0.17 \\
& $(0.24)$ & $(0.66)$ & $(0.61)$ & $(0.43)$ & $(1.43)$ & $(1.30)$ \\
\hline \multirow{2}{*}{ Riksbank Minutes Optimism } & 0.13 & $1.38 * *$ & 0.87 & $-0.88^{* * *}$ & -1.00 & 0.10 \\
& $(0.36)$ & $(0.68)$ & $(0.80)$ & $(0.29)$ & $(2.05)$ & $(1.00)$ \\
\hline \multirow{2}{*}{ Riksbank Minutes Pessimism } & -0.31 & 0.48 & 0.83 & $-3.39 * * *$ & -5.12 & -3.76 \\
& $(0.24)$ & $(0.79)$ & $(0.91)$ & $(0.78)$ & $(6.27)$ & $(2.55)$ \\
\hline $\mathrm{N}$ & 839 & 839 & 839 & 299 & 299 & 299
\end{tabular}

\section{h) Switzerland}

\begin{tabular}{lcccccc} 
& 3-month & 2-year & 10-year & 3-month & 2-year & 10 -year \\
\hline \multirow{2}{*}{ SNB Press Release Certainty } & -0.23 & 3.83 & $-6.89^{* *}$ & -3.50 & -1.27 & 2.40 \\
& $(13.67)$ & $(4.33)$ & $(3.10)$ & $(6.06)$ & $(2.25)$ & $(1.50)$ \\
\hline \multirow{2}{*}{ SNB Press Release Optimism } & -2.16 & 0.86 & $-2.18^{*}$ & -7.73 & 2.05 & -1.13 \\
& $(3.57)$ & $(1.61)$ & $(1.23)$ & $(10.16)$ & $(1.54)$ & $(1.25)$ \\
\hline \multirow{2}{*}{ SNB Press Release Pessimism } & -1.67 & -1.32 & $-2.96^{* *}$ & $5.56^{* * *}$ & 2.88 & -1.81 \\
& $(5.24)$ & $(1.54)$ & $(1.25)$ & $(1.78)$ & $(1.90)$ & $(1.22)$ \\
\hline N & 290 & 290 & 290 & 644 & 644 & 644
\end{tabular}

Notes: Shown are coefficients and standard deviation in brackets for estimates of equations (1) for the benchmark and ELB periods for each country. ${ }^{*}, * *$ and $* * *$ represent statistical significance at the $1 \%$, $5 \%$ and $10 \%$ levels, respectively. All regressions use Newey-West standard errors. $\mathrm{N}$ is the number of observations; dates when there are no news events are excluded from the sample. 
FIGURE 2

Data Dependence of 2 and 10-year Sovereign Bond Yields to News

(a) US, euro area, UK, and Switzerland
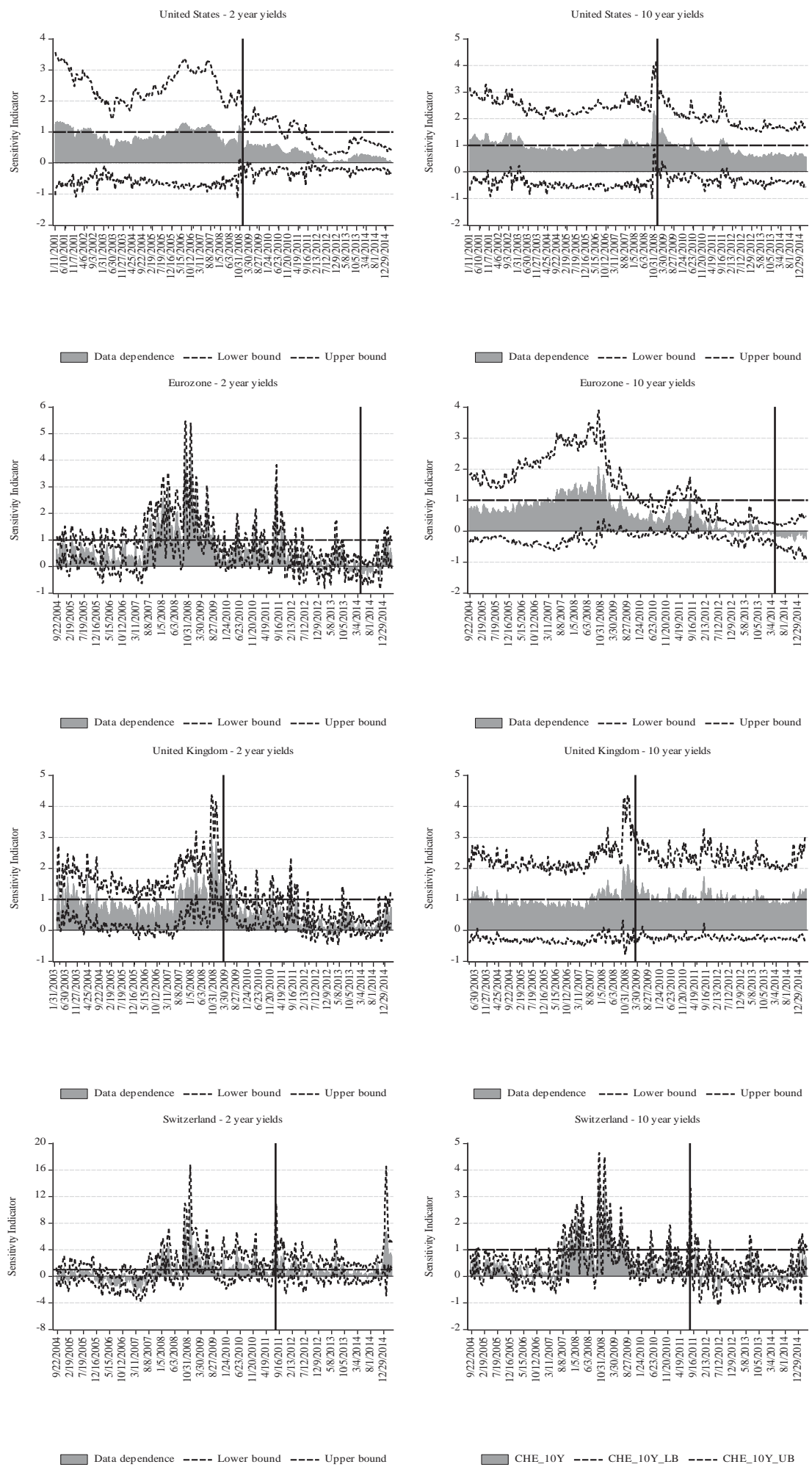
(b) France, Germany, Canada, and Sweden
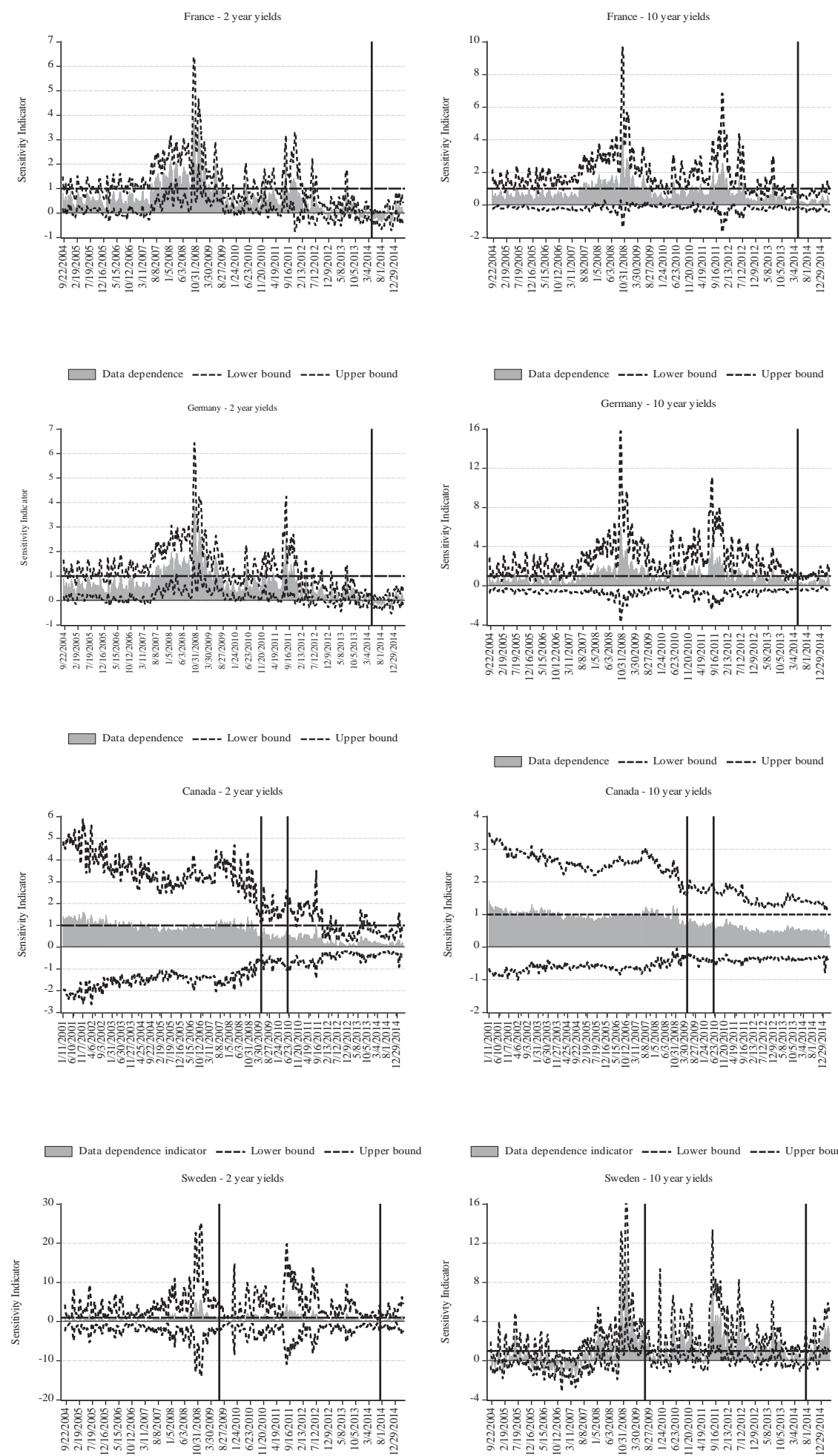
Notes: The graphs present the values of the 22-observation moving average of the fitted values from the following model (also see equation (3)): $f\left(\Theta_{\mathrm{t}}\right)=\theta+\varphi^{*}$ level $+\rho^{*}$ uncertainty $+0.5^{*}$ globaluncertainty where the level of yields is measured by the first principal component of 3-month, 2-year, 5-year, 10-year and 30-year domestic bond yields (where available), uncertainty is measured by the 10-day rolling standard deviation of the principal component, and globaluncertainty is the 10-day rolling standard deviation of the first principal component of US futures. For the US, global uncertainty is measured by the VIX. The benchmark samples, a period where rates are not constrained by the ELB, include the period where policy rates are at or below two percent. The data dependence measure is normalized to unity based on the pre-crisis benchmark (shaded area) while the lower and upper confidence intervals (CI) are dashed lines. The vertical lines indicate when the ZLB or ELB lower bounds are reached (refer to Table 1). 
Table 4

Value of the constraint to news at the $\operatorname{ELB}\left(f\left(\Theta_{t}\right)\right)$

\begin{tabular}{|c|c|c|c|c|c|c|c|c|}
\hline & GBR & USA & CAN & SWE & CHE & DEU & FRA & EUR \\
\hline 2-year & $0.30^{*}$ & $0.28^{*}$ & $0.49^{*}$ & $0.49^{*}$ & $0.38^{*}$ & $0.29^{*}$ & $0.03^{*}$ & $0.21^{*}$ \\
yield & $(-0.01 ;$ & $(-0.25 ;$ & $(-0.73 ;$ & $(-1.87 ;$ & $(-0.56 ;$ & $(-0.03 ;$ & $(-0.32 ;$ & $(-0.18 ;$ \\
& $0.62)$ & $0.82)$ & $1.71)$ & $2.85)$ & $1.33)$ & $0.62)$ & $0.38)$ & $0.59)$ \\
\hline $\mathbf{1 0 -}$ & $1.24^{*}$ & $0.79^{*}$ & $0.65^{*}$ & $1.28^{*}$ & $0.17^{*}$ & $0.41^{*}$ & $-0.19^{*}$ & $-0.15^{*}$ \\
year & $(0.34 ;$ & $(-0.33 ;$ & $(-0.31 ;$ & $(0.09 ;$ & $(-0.18 ;$ & $(-0.39 ;$ & $(-0.56 ;$ & $(-0.68 ;$ \\
yield & $2.15)$ & $1.91)$ & $1.61)$ & $2.48)$ & $0.51)$ & $1.21)$ & $0.19)$ & $0.40)$ \\
\hline
\end{tabular}

Notes: Displayed are the values of the level of constraint to news at the ELB (value of $f\left(\Theta_{t}\right)$ ) and the $95 \%$ confidence interval in brackets. As $f\left(\Theta_{\mathrm{t}}\right)$ is set to unity during the benchmark period-a period where yields are expected to respond normally to news - a value greater than one suggests higher than normal responsiveness to news and a value less than one represents lower than normal sensitivity to news. * indicates the mean value of $f\left(\Theta_{\mathrm{t}}\right)$ during the ELB period is statistically different than one. 